\title{
O ATAQUE À LIBERDADE DOCENTE E A DISCUSSÃO SOBRE GÊNERO E DIREITOS HUMANOS NA EDUCAÇÃO. O MULTICULTURALISMO COMO PROPOSTA DE RESISTÊNCIA
}

\author{
Marcos Vinicius Pereira Monteiro ${ }^{1}$ \\ Vera Helena Ferraz de Siqueira ${ }^{2}$
}

\section{RESUMO}

Este artigo situa e discute o ataque à liberdade docente, conforme vem se dando nos últimos anos, cerceando o debate sobre gênero no ambiente escolar. Nesse sentido, em um primeiro momento apresentamos uma reflexão acerca das propostas aprovadas ou em discussão em diferentes casas legislativas no Brasil que visam limitar a liberdade docente, e identificamos os movimentos de resistência que se opõem a estes ataques, principalmente juridicamente. A seguir abordamos a relação entre construção identitária, gênero e multiculturalismo como um referencial importante para subsidiar processos de resistência que contribuam para minimizar o impacto da censura prévia no chão de escola. Discutimos o que este cerceamento de liberdade implica para a pedagogia e para a educação, argumentando sobre o papel político do/a professor/a, e sobre a importância da pluralidade de ideias no ambiente escolar, conforme concebida a partir de uma determinada visão de multiculturalismo, essencial para garantir relações mais simétricas na sociedade.

Palavras-chave: Gênero e direitos humanos. Interculturalidade. Escola sem partido.

\section{THE ATTACK ON TEACHER FREEDOM AND THE DISCUSSION ON GENDER AND HUMAN RIGHTS IN EDUCATION. MULTICULTURALISM AS PROPOSAL OF RESISTANCE}

\begin{abstract}
This article situates and discusses the attack on teachers freedom, as has been happening in recent years, curtailing the debate about gender in the school environment. In this sense, we first present a reflection about the proposals approved or under discussion in different legislative houses in Brazil that aim to limit teaching freedom, and we identify the movements of resistance that oppose these attacks,

\footnotetext{
1 Doutorando em Educação em Ciências e Saúde (Universidade Federal do Rio de Janeiro). Professor do Colégio Pedro II. E-mail: profmarcosvmonteiro@gmail.com

2 Doutora em Educação (COLUMBIA UNIVERSITY). Professora do Programa de Pós-graduação em Educação em Ciências e Saúde da Universidade Federal do Rio de Janeiro. E-mail: verahfs@yahoo.com.br
} 
mainly juridically. Next, we address the relationship between identity construction, gender and multiculturalism as an important reference to support resistance processes that contribute to minimize the impact of prior censorship on the school site. We discuss what this freedom entails for pedagogy and for education, arguing about the political role of the teacher, and about the importance of plurality of ideas in the school environment, as conceived from a particular view of multiculturalism. This is essential for ensuring more symmetrical relationships in society.

Keywords: Gender and human rights. Interculturality. Unpolitical School

\section{EL ATAQUE A LIBERTAD DOCENTE Y LA DISCUSIÓN SOBRE GÉNERO Y DERECHOS HUMANOS EN LA EDUCACIÓN. LO MULTICULTURALISMO COMO PROPUESTA DE RESISTENCIA}

\section{RESUMEN}

Este artículo sitúa y discute el ataque a la libertad docente, conforme ocurre en los últimos años, coartando el debate sobre género en el ambiente escolar. En ese sentido, en primer lugar presentamos una reflexión acerca de las propuestas aprobadas o en discusión en diferentes casas legislativas en Brasil que tienen por objetivo limitar la libertad docente, e identificamos los movimientos de resistencia que se oponen a estos ataques, principalmente jurídicamente. A continuación abordamos la relación entre construcción identitaria, género e multiculturalismo como referente importante para subsidiar procesos de resistencia que contribuyan a minimizar el impacto de la censura previa en la escuela. Discutimos lo que esta coartación de libertad implica para la pedagogía y para la educación, argumentando sobre el papel político del profesor/a, y sobre la importancia de la pluralidad de ideas en el ambiente escolar, conforme concebida a partir de una determinada visión de multiculturalismo, esencial para garantizar relaciones más simétricas en la sociedad.

Palabras clave: Género y Derechos Humanos. Interculturalidad. Escuela sin partido

\section{INTRODUÇÃO}

Nos últimos tempos o debate sobre gênero no ambiente escolar vem enfrentando inúmeras hostilidades por parte de grupos conservadores. Isso se dá em um movimento transnacional presente em todos os continentes 3 , com elementos políticos e estratégias em comum. Tal movimento acusa escolas, currículos e professores/as de doutrinação, com a reafirmação de pontos

\footnotetext{
${ }^{3}$ Junqueira (2017) cita 32 nações na América do Sul, América Central, América do Norte, Ásia e Oceania onde têm ocorrido campanhas contra a "teoria/ideologia de gênero". Informa ainda que especialmente na África e Ásia, tematizações contra o gênero têm ficado mais a cargo de autoridades religiosas nacionais ou estrangeiras do que de um ativismo local. Não há por parte dos integrantes deste movimento transnacional, nenhum interesse pelo confronto acadêmico. O seu público alvo são principalmente gestores públicos, parlamentares, juristas, jornalistas, dirigentes escolares, eleitores.
} 
cristãos dogmáticos e gera pânico moral ao confrontar um suposto inimigo da "família tradicional" (representada pelo matrimônio heterossexual), justificando assim a necessidade de garantir legalmente que os pais tenham exclusividade no desenvolvimento da educação moral e sexual.

Qual o motivo da seleção de determinado conteúdo e não outro no currículo escolar? O que conta como conhecimento? Quais os grupos que atuam nessas escolhas? Quais os interesses em silenciar determinadas vozes? É neste campo de luta que os grupos que detém o poder simbólico afirmam para si a condição de padrão a ser seguido e representam o "outro" como alguém a ser corrigido ou deixado à margem. Refletir e avançar no entendimento dessas questões nos faz lançar mão da mencionada concepção de currículo inspirada nos Estudos Culturais, que entre outros aspectos, dá voz aos conhecimentos das comunidades que em um passado não muito distante eram completamente silenciadas na instituição escolar. Nessa concepção, os/as professores/as possuem importância única na busca de uma sociedade que valorize a multiplicidade cultural.

Assumimos o currículo como um campo de lutas que atua como construtor identitário, onde diferentes grupos tentam estabelecer sua hegemonia. No embate atual em torno das mencionadas questões, enfatizamos a importância do multiculturalismo, um "campo teórico, prático e político, voltado à valorização da diversidade cultural e ao desafio dos preconceitos" (CANEN e XAVIER, 2005, p. 335/336). Como campo prático, articulam-se questionamentos sobre a construção e reprodução de preconceitos e estereótipos e se valoriza a pluralidade cultural, com implicações para o papel da escola e o desenvolvimento da cidadania. Damos relevo a uma perspectiva importante que nos últimos anos vem sendo construída sobre esse campo, interrelacionando-o com os direitos humanos.

Com tais questões em vista, neste artigo discutimos a atuação e o papel docente tendo em vista ataques à sua liberdade. Fazemos uma reflexão sobre propostas aprovadas ou em discussão em diferentes casas legislativas no Brasil que visam limitar a liberdade docente, e identificamos os 
movimentos de resistência que se opõem a estes ataques, principalmente juridicamente. A seguir abordamos a relação entre construção identitária, gênero e multiculturalismo como um referencial importante para subsidiar processos de resistência que contribuam para minimizar o impacto da censura prévia na escola. Discutimos o que este cerceamento de liberdade implica para a pedagogia e para a educação, argumentando sobre o papel político do/a professor/a, e sobre a importância da pluralidade de ideias no ambiente escolar, essencial para garantir relações mais simétricas na sociedade.

\section{Ataques conservadores à liberdade de expressão na escola}

Nos últimos anos, o debate sobre gênero no ambiente escolar tem obtido destaque em diversas casas legislativas pelo país. Deputados/as e vereadores/as, com o apoio de entidades religiosas e de associações como o "Escola sem partido", vêm excluindo alguns termos das leis que versam sobre educação e aprovando leis que regulamentam aquilo que o/a professor/a pode fazer em sala de aula. Os termos que vêm sendo excluídos dos documentos legais são principalmente "Gênero", "Igualdade de gênero" e "Orientação sexual". Alegam que lutam contra a "ideologia de gênero", utilizando este termo para significar que a discussão do tema na escola é feita com o intuito de realizar uma dominação ou alienação dos/as alunos/as, que seriam vulneráveis a uma ação docente que ocorre em um ambiente de desequilíbrio de poder e que a sua discussão distorce os conceitos de homem e mulher, o que levaria ao término da "família tradicional".

Junqueira (2017) constrói um contra-argumento incisivo ao fazer a distinção entre gênero como conceito e uma "teoria/ideologia de gênero". Aponta para a impropriedade de se responsabilizar as mudanças preconizadas nos Estudos de Gênero e no feminismo pela transformação da escola em um campo de doutrinação de gênero, pela privação das crianças do direito à família etc. O autor afirma que o termo ideologia de gênero denunciado pelas "cruzadas antigênero": 
É um sintagma forjado para operar como uma arma política, enquanto dispositivo retórico, metadiscursivo, paródico e reacionário. Um dispositivo que, de um lado, age para conter ou anular o potencial crítico e emancipador do feminismo e dos Estudos de Gênero e deslegitimar atores e reivindicações neles fundamentados. De outro, enseja a valorização, o acúmulo e a recuperação de capital social e político por parte de setores tradicionalistas e ultraconservadores - especialmente o campo eclesiástico, interessado em manter e ampliar sua influência, inclusive em temas e espaços não estritamente religiosos ou que, em sociedade laicas, não deveriam ser religiosos, como a educação e a saúde pública. [...] (JUNQUEIRA, 2017, p. 45-46).

Fernando Penna, professor da Universidade Federal Fluminense, em entrevista ao Jornal O Globo, afirmou que para explicar este movimento, é necessário retornar a 2011 quando o governo Federal se preparava para distribuir um material de combate à homofobia que acabou apelidado de "kit gay" por parlamentares que criaram essa bandeira para se promover. 0 kit acabou vetado depois de muita polêmica e em sua opinião foi um marco importante na origem do que hoje é chamado de combate à dita "ideologia de gênero"4. Para o professor:

A ideologia de gênero é um termo cunhado para desqualificar o debate sobre as desigualdades, sobre os papeis sociais, e pregar que o objetivo real é a erotização infantil, a transformação de jovens em gays e lésbicas ou o combate à família tradicional [...]. Aliado a isso, há circulação de notícias falsas em redes sociais que causam um pânico moral muito grande. E as famílias, numa atitude compreensível, ficam apavoradas (MARIZ; BARRETTO, 2017).

Vários são os exemplos em tempos recentes da força de organização e pressão desses grupos. O Plano Nacional de Educação (BRASIL, 2014a),

\footnotetext{
4 Junqueira (2017) afirma que possivelmente o sintagma "ideologia de gênero" foi empregado pela primeira vez na obra L'Évangile face au désordre mondial (SCHOOYANS, 1997) que contava com prefácio do então cardeal Joseph Ratzinger. Em abril do ano seguinte, tal termo apareceu pela primeira vez em um documento eclesiástico, foi na nota da Conferência Episcopal do Peru, intitulada La ideologia de género: sus peligros y alcances, (REVOREDO, 1998). E finalmente no ano 2000 ele esteve presente em um documento da Cúria Romana no documento: Família, Matrimônio e "uniões de fato", do Conselho Pontifício para a Família (PONTIFíCIO, 2000). Além destes documentos, Joseph Ratzinger, já como Papa Bento XVI, citou o termo em importantes pronunciamentos. Em seu "Discurso à Cúria Romana por Ocasião dos Votos de Feliz Natal" (BENTO XVI, 2008), descreveu gênero como algo que, ao motivar a autoemancipação do homem em relação ao Criador, contrariaria e desprezaria a natureza, e poderia levá-lo à autodestruição. Já em 2012, por ocasião do "Discurso à Cúria Romana na Apresentação de Votos Natalícios", Bento XVI não apenas prosseguiu no mesmo caminho anterior, mas fez uma condenação incisiva sobre o tema (BENTO XVI, 2012).
} 
que determina diretrizes, metas e estratégias para a política educacional do país entre os anos de 2014 e 2024, teve durante sua passagem pelo Senado os mencionados termos excluídos. O texto inicial foi nomeado como Projeto de Lei 8053/2010 (BRASIL, 2010). A redação final aprovada pela Câmara dos Deputados e encaminhada ao Senado em outubro de 2012 possuía os seguintes trechos:

Art. $2^{\circ}$ São diretrizes do PNE: [...] III - superação das desigualdades educacionais, com ênfase na promoção da igualdade racial, regional, de gênero e de orientação sexual.

Estratégia 3.12 da Meta 3: implementar políticas de prevenção à evasão motivada por preconceito e discriminação racial, por orientação sexual ou identidade de gênero, criando rede de proteção contra formas associadas de exclusão.

Entretanto, ao retornar da Casa revisora, o Projeto de Lei voltou como um substitutivo (BRASIL, 2013) no qual foi concretizada a exclusão dos termos, passando a vigorar a seguinte redação, que foi aprovada pela Câmara dos Deputados:

Art. 2o São diretrizes do PNE: [...] III - superação das desigualdades educacionais, com ênfase na promoção da cidadania e na erradicação de todas as formas de discriminação;

Estratégia 3.13 da Meta 3: implementar políticas de prevenção à evasão motivada por preconceito ou quaisquer formas de discriminação, criando rede de proteção contra formas associadas de exclusão.

Após a aprovação deste texto, coube aos Estados e Municípios elaborarem os seus "Planos de Educação" num prazo de dois anos e alguns destes também retiraram as palavras relacionadas à "ideologia de gênero" de seus documentos finais após sofrerem as mesmas pressões, como por exemplo: Cascavel (PR), Paranaguá (PR), Blumenau (SC), Tubarão (SC), Palmas (TO), Ipatinga (MG) e Novo Gama (GO). Diante disso o Conselho Nacional de Educação, órgão vinculado ao Ministério da Educação, enviou uma nota pública (BRASIL, 2015), às Casas Legislativas e à sociedade brasileira, onde manifesta preocupação com os referidos planos, que:

[...] têm omitido, deliberadamente, fundamentos, metodologias e procedimentos em relação ao trato das questões relativas à diversidade cultural e de gênero [...] sobre o qual não pode permanecer qualquer dúvida quanto à propriedade de seu tratamento no campo da educação. [...] a ausência ou insuficiência 
de tratamento das referidas singularidades fazem com que os planos de educação que assim as trataram sejam tidos como incompletos e que, por isso, devem ser objeto de revisão (BRASIL, 2015, p. 2).

Por outro lado, a Conferência Nacional dos Bispos do Brasil, instituição que congrega os Bispos da igreja Católica no país, divulgou uma Nota assinada pela sua presidência, criticando os Estados e municípios que incluíram questões sobre o gênero em seus Planos de Educação:

\begin{abstract}
Homem e mulher ele os criou [...]. A tentativa de inclusão da ideologia de gênero nos Planos Estaduais e Municipais de Educação contraria o Plano Nacional de Educação, aprovado no ano passado pelo Congresso Nacional, que rejeitou tal expressão. Pretender que a identidade sexual seja uma construção eminentemente cultural, com a consequente escolha pessoal, como propõe a ideologia de gênero, não é caminho para combater a discriminação das pessoas por causa de sua orientação sexual. [...] A ideologia de gênero vai no caminho oposto e desconstrói o conceito de família, que tem seu fundamento na união estável entre homem e mulher. A introdução dessa ideologia na prática pedagógica das escolas trará consequências desastrosas para a vida das crianças e das famílias (CNBB, 2015, p. 1).
\end{abstract}

A Procuradoria Geral da República também participou deste debate, recorrendo ao Supremo Tribunal Federal através de uma arguição de descumprimento de preceito fundamental contra os municípios que objetivavam vedar políticas e ações educacionais com relação a gênero e diversidade sexual. A Procuradoria considerou que a abordagem destes conteúdos não se colocaria em oposição ao papel da família. Foi requerida então uma liminar para suspender a eficácia destas leis, para que uma possível demora processual não acarretasse danos irreparáveis ao direito à igualdade, à liberdade de aprender, de pesquisar e de ensinar e ao pluralismo de ideias. "A lei, ademais, ao sonegar dos estudantes discussão sobre temas concernentes a sexualidade e a gênero, contribui para perpetuar a cultura de violência, tanto psicológica quanto física, contra vastas parcelas da população LGBT do País [...]" (BRASIL, 2017). O pedido de liminar foi deferido pelo ministro Luis Roberto Barroso e encaminhado para referendo do plenário do Supremo Tribunal Federal. Em sua decisão, o ministro afirmou: 
[...] não se deve recusar aos alunos acesso a temas com os quais inevitavelmente travarão contato na vida em sociedade. A educação tem o propósito de prepará-los para ela [...]. Quanto maior é o contato do aluno com visões de mundo diferentes, mais amplo tende a ser o universo de ideias a partir do qual pode desenvolver uma visão crítica, e mais confortável tende a ser o trânsito em ambientes diferentes dos seus. É por isso que o pluralismo ideológico e a promoção dos valores da liberdade são assegurados na Constituição e em todas as normas internacionais antes mencionadas [...]. Não tratar de gênero e de orientação sexual no âmbito do ensino não suprime o gênero e a orientação sexual da experiência humana, apenas contribui para a desinformação das crianças e dos jovens a respeito de tais temas, para a perpetuação de estigmas e do sofrimento que deles decorre. (BARROSO, 2017a, p. 8/9)

Impedir a alusão aos termos gênero e orientação sexual na escola significa conferir invisibilidade a tais questões. Proibir que o assunto seja tratado no âmbito da educação significa valer-se do aparato estatal para impedir a superação da exclusão social e, portanto, para perpetuar a discriminação. Assim, também por este fundamento - violação à igualdade e à dignidade humana [...] (BARROSO, 2017a, p. 11)

Também influente neste embate de forças é a associação "Escola sem Partido"; consta de sua página eletrônica tratar-se de "iniciativa conjunta de estudantes e pais preocupados com o grau de contaminação políticoideológica das escolas brasileiras, em todos os níveis: do ensino básico ao superior". Esta associação surgiu em $2004^{5}$ e para Penna (2017) e Espinosa e Queiroz (2017) não foi uma ameaça levada a sério, principalmente por não possuir consistência teórica e jurídica e não utilizar o meio acadêmico para divulgação de suas ideias; entretanto, a partir de 2015, ganhou capilaridade junto à sociedade. Suas ideias são divulgadas estimulando o patrulhamento de supostas ações de doutrinação realizadas por professores/as e materiais didáticos. Apesar de se autodenominar "sem partido", induzindo uma criminalização da política, próximo ao período das eleições municipais de 2016 disponibilizou um link "Escola Sem Partido nas eleições", que divulgava a candidatura de pessoas que se comprometeram a apoiar ou apresentar um projeto contra esta possível "contaminação políitico-ideológica". Quanto à nomenclatura da associação, Ramos (2017, p. 85) afirma:

\footnotetext{
${ }^{5}$ Informação presente na página eletrônica da associação em: http://escolasempartido.org/midia/395-entrevista-de-miguel-nagib-a-revista-profissaomestre. Acesso em 4 de outubro de 2017.
} 
O nome "sem partido" também não é inocente: sob a roupagem de se defender que a escola não "tome partido" de alguma ideologia, aproveita-se da reação que a sociedade brasileira tem mostrado em relação aos partidos políticos - face a marcas fisiológicas que atravessam a histórica de vários deles - como artifício de sedução e adesão dos cidadãos a suas ideias. Com isto, esvazia-se profundamente o sentido da política para que a sociedade - na forma de um consentimento ativo ou passivo - delegue o poder àqueles que historicamente oprimem os que não se enquadram nos padrões hegemônicos de uma classe dominante autoritária e escravocrata. Assim, o Escola sem Partido é uma estratégia dessa classe dominante que não se inibe de se apoiar no medo e na coerção para defender seus interesses.

Essa associação estimula que pais/responsáveis processem escolas e professores/as que possam, segundo eles, estar se aproveitando "da audiência cativa dos alunos, para promover suas próprias concepções, opiniões e preferências políticas e ideológicas", disponibilizando inclusive um modelo de notificação extrajudicial, denominado por eles "arma das famílias contra a doutrinação nas escolas" (ESCOLA SEM PARTIDO, sem data), que deve ser levado para a assinatura dos/as docentes, como um comunicado prévio de que estariam sob vigilância. Tal documento possui um claro tom de intimidação, com ameaças de processo, prisão e perda de emprego e bens.

O documento é longo, possui 22 itens e demonstra claramente o modo de pensar deste grupo. Nele, os professores são acusados de usarem argumentos como o combate à homofobia, ao preconceito, à AIDS etc. para aprisionarem seus "inexperientes alunos" em "gaiolas ideológicas" (item 2) e de se intrometerem ilegalmente na formação moral dos alunos (item 5). A partir daí, são mencionados os termos da Lei 4898/65 (conhecida como Lei de Abuso de Autoridade) para respaldar o estabelecimento de sanções contra os professores que "atentarem contra a "liberdade" dos alunos/as: condenação de até 6 meses de detenção, perda do cargo, impedimento de exercício de qualquer outra função pública pelo "prazo de até três anos" (item 8) e a possibilidade de os professores "abusadores de crianças e adolescentes" perderem o seu patrimônio, caso os pais decidam processálos (item 9).

Principalmente no item 14 do documento nota-se a intenção de intimidar os professores principalmente em relação a sua possível 
abordagem de temas relacionados a gênero e sexualidade, com acusações ao MEC por oferecer respaldo, com os Parâmetros Curriculares Nacionais, a "desvios de conduta" dos docentes:

\begin{abstract}
14 - Isto se aplica de modo especial ao campo da sexualidade humana, onde praticamente tudo é objeto de regulação estrita por parte da moral. Tome-se, por exemplo, a relação de temas cuja abordagem é sugerida ilegalmente pelo MEC, no caderno de orientação sexual dos Parâmetros Curriculares Nacionais: masturbação, homossexualidade, hermafroditismo, transexualismo, aborto, prostituição, erotismo, pornografia, desempenho sexual, disfunções sexuais, parafilias, gravidez na adolescência, doenças sexualmente transmissiveis e questões de gênero. Ora, é praticamente impossivel a um professor discorrer sobre esses assuntos em sala de aula, sem acabar afrontando, de uma só vez, o princípio da laicidade do Estado, a liberdade de consciência e de crença dos alunos e o direito dos seus pais a que eles recebam a educação religiosa e moral que esteja de acordo com suas próprias convicções.
\end{abstract}

Como fundamento para silenciar os docentes são mencionados o princípio constitucional da laicidade do Estado e o direito dos pais "a que seus filhos recebam a educação religiosa e moral que esteja de acordo com suas próprias convicções" (item 16). No fechamento do documento (item 18) é esclarecido para os professores que os filhos estão cientes dessa notificação e que têm orientação para reportar "de forma detalhada" possíveis "transgressões à sua liberdade de consciência e de crença".

É este tipo de movimento que nos últimos tempos vem inspirando políticos dos mais diversos níveis de governo por todo o país. Há inclusive, no Congresso Nacional, o Projeto de Lei 7180/2014 (BRASIL, 2014b) que "inclui entre os princípios do ensino o respeito às convicções do aluno, de seus pais ou responsáveis, dando precedência aos valores de ordem familiar sobre a educação escolar nos aspectos relacionados à educação moral, sexual e religiosa". Este projeto, que também encontrou apoio na bancada evangélica, notadamente a fatia ligada a igrejas neopentecostais (ESPINOSA; QUEIROZ, 2017), insinua que está em curso nas escolas, universidades e concursos públicos pelo Brasil um grande projeto de cooptação e doutrinação político-ideológica. Entretanto, o projeto não define claramente o que seria esta doutrinação. Após uma análise da 
página eletrônica do Escola sem partido, Penna (2017) afirma ter encontrado um caminho para tal compreensão e sinaliza para a incoerência e a impossibilidade de se adotar a requerida neutralidade na escola:

\begin{abstract}
Temos aqui uma definição do que seria essa prática: você pode estar sendo vítima de doutrinação ideológica quando seu professor se desvia frequentemente da matéria objeto da disciplina para assuntos relacionados ao noticiário político ou internacional. Uma dissociação entre o que é a matéria e o que está acontecendo no mundo, na realidade do aluno. A afirmativa de que o professor não poderia discutir essa realidade, ele teria que se ater à sua matéria - e nós sabemos que isso na prática é impossível, porque dialogar com a realidade do aluno é um princípio educacional estabelecido para tornar o ensino das disciplinas significativo. Adota ou indica livros e publicações de autores identificados com determinada corrente ideológica: eu sempre faço o mesmo desafio - gostaria que alguém me indicasse um livro que não é identificado com uma corrente ideológica.
\end{abstract}

Com relação ao Projeto de Lei, a Procuradoria Federal dos Direitos do Cidadão emitiu nota técnica informando que " [...] a iniciativa nasce eivada de inconstitucionalidade" (BRASIL, 2016a, p. 1), salienta também que o Projeto de Lei reflete $\mathrm{o}$ inconformismo com as conquistas democráticas alcançadas em nossa sociedade no processo constituinte, com a construção de uma sociedade que deve estar aberta a diferentes visões de mundo. Situa a escola como lugar estratégico para a emancipação política e para o fim de ideologias excludentes e discriminatórias e destaca as razões pelas quais o Projeto de Lei subverte a atual ordem constitucional, como ao confundir a educação escolar com aquela que é fornecida pelos pais e ao negar a possibilidade ampla de aprendizagem e a pluralidade de ideias.

Também se posicionou o Conselho Nacional dos Direitos Humanos, o qual através de resolução (CNDH, 2017), repudiou iniciativas que restringem o debate de determinados assuntos no ambiente escolar como política, gênero, sexualidade, combate à discriminação, reforçando a inconstitucionalidade destas iniciativas e encaminhando este documento para dezenas de órgãos e associações.

Relatores da Organização das Nações Unidas também criticaram a mencionada ofensiva, enviando um documento ao governo brasileiro no 
qual alertam que "se aprovadas, as leis podem representar uma violação ao direito de expressão nas salas de aulas e uma censura significativa" (CHADE; TOLEDO, 2017). Sinalizam ainda que o projeto abre brechas arbutrárias para que autoridades e os responsáveis pelos/as alunos/as interfiram nas escolas e pedem a revisão do mesmo, visando atender aos padrões internacionais de direitos humanos, pois da forma como foi apresentado poderia impedir o debate de temas como diversidade e direito de minorias. Consideramos tal reflexão pertinente, haja vista que, o Escola sem Partido entrou com ação na justiça e obteve êxito contra o Instituto Nacional de Estudo e Pesquisas Educacionais Anísio Teixeira (INEP/MEC), questionando o critério de anulação das redações que contrariem os direitos humanos no Exame Nacional do Ensino Médio (Enem). Para os representantes do movimento, este critério é subjetivo e injusto, pois ninguém pode ser obrigado a dizer o que não pensa para entrar numa universidade. (CASTRO, 2017).

A mesma inspiração tem a Lei número 7800 de 2016 do Estado de Alagoas, denominada pelos/as docentes como "Lei da Mordaça". Como fato novo, a lei obriga a Secretaria Estadual de Educação a promover cursos de ética para os professores e a comunidade escolar "a fim de informar e conscientizar os educadores, os estudantes e seus pais ou responsáveis sobre os limites éticos e jurídicos da atividade docente [...]" (ALAGOAS, 2016). O Ministério da Educação entrou com ação contra esta Lei, afirmando que a medida "contradiz o princípio constitucional do pluralismo de ideias e concepções pedagógicas [...] o cerceamento do exercício docente restringe o papel do professor e estabelece censura, além de prejudicar o livre debate no ambiente escolar" (BRASIL, 2016b). Um dado curioso é que a mencionada Lei foi chamada por seus criadores "Lei Escola Livre"; apenas não fica claro é para o quê a escola ficaria livre ou ficaria livre de quem? O governador vetou a Lei, entretanto o veto foi derrubado pela Assembleia Legislativa de Alagoas. A Lei foi suspensa liminarmente através de ação direta de inconstitucionalidade impetrada pela Confederação Nacional dos Trabalhadores em Estabelecimentos de Ensino- CONTEE, através de decisão monocrática do Ministro Roberto Barroso em que afirmou: 
[...] os pais não podem pretender limitar o universo informacional de seus filhos ou impor à escola que não veicule qualquer conteúdo com o qual não estejam de acordo. Esse tipo de providência [...] significa impedir o acesso dos jovens a domínios inteiros da vida, em evidente violação ao pluralismo e ao seu direito de aprender. A educação é, justamente, o acúmulo e o processamento de informações, conhecimentos e ideias que proveem de pontos de vista distintos, experimentados em casa, no contato com amigos, com eventuais grupos religiosos, com movimentos sociais e, igualmente, na escola. (BARROSO, 2017b, p. 20).

Assim é que a decisão do juiz invoca o direito dos jovens ao livre acesso a pontos de vista diversos, de múltiplas fontes, negado no texto da Lei. A seguir é desconstruída a própria concepção de neutralidade e, portanto, a possibilidade de uma educação totalmente isenta, e de um professor cuja visão de mundo possa ser livre de opiniões e de ideologias.

A própria concepção de neutralidade é altamente questionável, tanto do ponto de vista da teoria do comportamento humano, quanto do ponto de vista da educação. Nenhum ser humano e, portanto, nenhum professor é uma "folha em branco" [...]. Em virtude disso, alguns professores têm mais afinidades com certas questões morais, filosóficas, históricas e econômicas; ao passo que outros se identificam com teorias diversas. Se todos somos [...] produto das nossas vivências pessoais, quem poderá proclamar sua visão de mundo plenamente neutra? A própria concepção que inspira a ideia da "Escola Livre" - contemplada na Lei 7800/2016 - parte de preferências políticas e ideológicas. (BARROSO, 2017b, p. 21).

A afirmação da liberdade do processo educativo é, por sua vez, reafirmada pelo Ministro, evidenciando como a Lei 7800 implica um inaceitável cerceamento da liberdade docente através de constrangimentos e perseguições:

A Lei 7.800/2016 traz, ainda, previsões de inspiração evidentemente cerceadora da liberdade de ensinar assegurada aos professores, que evidenciam o propósito de constranger e de perseguir aqueles que eventualmente sustentem visões que se afastam do padrão dominante, estabelecendo vedações - extremamente vagas - tais quais: (i) proibição de conduta por parte do professor que possa induzir opinião político-partidária, religiosa ou mesmo filosófica nos alunos (art. $2^{\circ}$ ); (ii) proibição de manifestar-se de forma a motivar os alunos a participar de manifestações, atos públicos ou passeatas (art. $3^{\circ}$, III); (iii) dever de tratar questões políticas, socioculturais e econômicas, "de forma justa", "com a mesma profundidade", abordando as principais teorias, opiniões e perspectivas a seu respeito, concorde ou não com elas (art. $3^{\circ}$, IV). (BARROSO, 2017b, p. 22). 
No lúcido parecer é enfatizada a educação em seu papel emancipador, que não se limita à transmissão do conhecimento técnico científico, mas inclui suas dimensões políticas e filosóficas:

Só pode ensinar a liberdade quem dispõe de liberdade. Só pode provocar o pensamento crítico, quem pode igualmente proferir um pensamento crítico. Para que a educação seja um instrumento de emancipação, é preciso ampliar o universo informacional e cultural do aluno, e não reduzi-lo, com a supressão de conteúdos políticos ou filosóficos, a pretexto de ser o estudante um ser "vulnerável". (BARROSO, 2017b, p. 24).

O desrespeito evidenciado na Lei aos valores tutelados pela Constituição serve de embasamento ao parecer quanto à valorização do profissional da educação e a inadmissibilidade de sua vigilância ideológica:

Vale notar, ademais, que a norma impugnada expressa uma desconfiança com relação ao professor. Os professores têm um papel fundamental para o avanço da educação e são essenciais para a promoção dos valores tutelados pela Constituição. Não se pode esperar que uma educação adequada floresça em um ambiente acadêmico hostil, em que o docente se sente ameaçado e em risco por toda e qualquer opinião emitida em sala de aula. A lei impugnada, nesta medida, desatende igualmente ao mandamento constitucional de valorização do profissional da educação escolar. (BARROSO, 2017b, p. 25).

Com relação a este último tópico, órgãos da imprensa já noticiaram o sentimento de patrulhamento que vem acometendo professores/as em sua prática diária. Reportagem do Jornal O Globo (FERREIRA; GRANDELLE, 2017) relatou casos em que professores/as afirmam uma hostilidade maior dentro de sala de aula e que a sensação de vigilância cresceu exponencialmente, afetando conteúdos, práticas e até a cor da roupa que eles vestem para trabalhar. Relatam, por exemplo, que alunos/as já se queixaram de debates conduzidos sobre temas como racismo e/ou homofobia; outro relato foi de uma professora que teve sua aula gravada sem que ela soubesse e sua opinião sobre eleitores de determinado político foi exposta em redes sociais; outros/as professores/as foram acusados de realizar doutrinação ideológica; uma auxiliar de coordenação de um colégio no Rio de Janeiro informou que recebe e-mails com denúncias sobre os conteúdos ministrados nas aulas, o 
que segundo ela é um fenômeno recente, pois antigamente as famílias tinham mais confiança nas escolas e isto motivou uma mudança na linha pedagógica da instituição, pois agora temas considerados polêmicos devem ser submetidos à direção e à aprovação dos pais.

Diversos autores que escreveram nos últimos tempos sobre este clima que vem se instalando nas escolas, como Souza e Oliveira assinalam o risco da criminalização do/a docente e de uma paranoia social pois estimula o patrulhamento ideológico dos professores e o denuncismo vazio, prevendo que as secretarias de educação tenham um canal de comunicação destinado ao recebimento de reclamações relacionadas ao descumprimento da lei. Ainda segundo os autores, o resultado desta proposição é a paranoia social tal e qual vivenciada pela Alemanha nazista e pela União Soviética stalinista. Algebaile (2017) acrescenta que não é preciso haver a aprovação do projeto para que se cumpra parte dos efeitos, através de autocensura, constrangimento e coibição de comportamentos e práticas que possam, mesmo remotamente, ser identificados como doutrinação ou "desrespeito às convicções morais da família". Para Ramos (2017), mesmo que várias análises já tenham sinalizado sobre a inconstitucionalidade do projeto, o que mais preocupa é o consentimento ativo dos cidadãos, pois isto já é o suficiente para se configurar um clima de assédio moral no interior da escola e de toda a sociedade. Bárbara, Cunha e Bicalho (2017) afirmam sua preocupação com o processo de colocar o/a professor/a como elemento perigoso "que precisa ser contido, calado e amordaçado para não ameaçar e contrariar a liberdade de consciência e descrença dada pela educação familiar" (p. 108).

Sobre a relação entre escola e ideologia, Souza e Oliveira (2017, p. 128) sustentam que a escola possui em sua gênese ideologias relacionadas à formação do indivíduo, por exemplo, no controle do tempo escolar, na disposição de alunos enfileirados um atrás do outro, no peso dado a diferentes disciplinas etc. E acrescenta que o que o projeto prevê é a criminalização de uma ideologia em benefício de outra. 
Até mesmo a discussão sobre sexualidade e o combate à homofobia na escola estão ameaçados por lei no município de Nova Iguaçu-RJ (questionada pelo Ministério Público por inconstitucionalidade) que proíbe:

\begin{abstract}
Art. $1^{\circ}[\ldots]$ A distribuição, exposição e divulgação de livros, publicações, cartazes, filmes, vídeos, faixas ou qualquer tipo de material, didático ou paradidático, contendo orientações sobre a diversidade sexual nos estabelecimentos de Ensino da rede pública municipal da Cidade de Nova Iguaçu.

Parágrafo Único: O material a que se refere o caput deste artigo é todo aquele que, contenha orientações sobre a prática de homoafetividade, de combate à homofobia, de direitos de homossexuais, da construção da heterormatividade ou qualquer assunto correlato (NOVA IGUAÇU, 2016).
\end{abstract}

Esta ofensiva busca retirar a autonomia docente, limitando seu trabalho a reproduzir aquilo determinado por cartilhas ou manuais confeccionados por pessoas/entidades distantes da realidade escolar, transformando o/a professor/a em um/a instrutor/a ao invés de um/a educador/a e os/as alunos/as em passivos receptores de conteúdos e técnicas, distantes da realidade social. Na opinião de Souza e Oliveira (2017, p. 128) "Para os autores da lei, o mundo do trabalho e o projeto de sociedade com a qual eles sonham não necessitam de cidadãos conscientes, questionadores e transformadores de uma realidade injusta que beneficia apenas as elites". De maneira alguma será possivel refletir sobre diferenças silenciando-as, ou adotando um modelo de educação bancária, depositando conhecimentos nos discentes, pois nesse caso, a escola ficará ao lado daqueles que detém o poder, reproduzindo estereótipos, discriminações e gerando o fracasso dos menos empoderados.

Sobre este tipo de embate, Giroux (2003) menciona um erro comum de quem, acusa a pedagogia, cujo objetivo seria informar e empoderar, como algo doutrinário, chamando atenção para a importância de se distinguir entre o que pode ser chamado de uma educação política daquilo que é uma educação politizadora. Esclarece ainda que a educação política significa reconhecer que as escolas e outros espaços culturais não podem abstrair-se das condições socioculturais e econômicas dos/as discentes, de suas famílias e de suas comunidades, ensinando os estudantes 
a correr riscos, fazer perguntas, desafiar aqueles no poder, propiciando ainda a oportunidade deles/as alterarem a estrutura do horizonte pelo qual suas identidades, valores e desejos são moldados, percebendo como o poder opera sobre eles, através deles e por eles. Por outro lado, a educação politizadora, sugere uma visão e prática de educação conservadora com um discurso de neutralidade e de negação da tomada de consciência das relações de poder envolvidos, recusando a abordar uma agenda política.

Nesta seção evidenciamos como diferentes grupos conservadores estão se articulando e encaminhando suas demandas, enquanto outras vozes buscam resistir, principalmente nos âmbitos acadêmico e jurídico. Um conselho é dado por Apple para fortalecer tais processos de resistência, o que pressupõe, entender como a direita torna seu discurso hegemônico:

Não vamos manipular a realidade da forma cínica como a direita faz, mas ela é extremamente inteligente no modo como faz. Eles entendem Gramsci muito melhor do que a esquerda. Entendem que para vencer, ganhar o Estado, você precisa ganhar primeiro a Sociedade Civil; eles entendem que a luta em torno da consciência das pessoas e do conhecimento é absolutamente crucial. (SILVA; MARQUES; GANDIN, 2012 p.177).

\section{Questões de gênero, multiculturalismo e a educação em direitos humanos}

As relações de gênero estão intrinsecamente ligadas às relações de poder, pois no interior delas são instituídas as desigualdades. Disputas teóricas e políticas marcaram ao longo dos anos a discussão da noção de gênero e das relações entre as categorias sexo/gênero e poder. Nos anos 1940 Simone de Beauvoir (1980) deu evidência ao papel central da cultura na construção das identidades, quando sugeriu que não se nasce mulher, mas torna-se mulher. Scott (1995), no final da década de 1980, influenciada pelas correntes pós-estruturalistas, passa a postular a noção de gênero como elemento constitutivo das relações sociais baseado nas diferenças percebidas entre os sexos, sendo desta forma principalmente uma maneira de significar as relações de poder. Ela diz que o gênero é uma categoria social imposta sobre um corpo sexuado, oferecendo um meio para distinguir a prática sexual dos papéis atribuídos as mulheres e aos homens. Desta 
forma, concebe o sexo como biológico e o gênero como cultural. Posteriormente, Butler (2015) critica o modelo binário sexo/gênero, questionando a premissa que sexo é natural e gênero construído, indicando que ao invés, sexo é também discursivo como gênero. A noção de "identidade de gênero", problematizada por Butler, oportuniza a compreensão de que o sexo atribuído à criança no nascimento não corresponde, necessariamente, com a identidade de gênero que teria ao crescer. Essa perspectiva abre possibilidade de subversão das identidades ao assumir que o que percebemos como realidade - no caso a nossa identidade de gênero- tem por determinante o sistema de signos e convenções solidamente fixadas na nossa sociedade.

Ao problematizar a questão da identidade de gênero, Butler questiona também a universalidade e unidade do sujeito do feminismo: "O nós feminista é sempre e somente uma construção fantasística, que tem seus propósitos, mas que nega a complexidade e a indeterminação interna do termo, e só se constitui por meio da exclusão de parte da clientela, que simultaneamente busca representar" (BUTLER, 2015, p. 245). Esta dificuldade em definir o que constitui a "categoria das mulheres" ocorre uma vez que a identidade feminina não poderia ser separada, por exemplo, das categorias de classe social, raça, sexual, regional ou outros eixos de relações de poder que em suas intercessões políticas e culturais acabam por criar noções singulares de identidade. Assim é que a teoria feminista oferece respaldo para pensar os desequilíbrios nas relações de gênero; Judith Butler, ao complexificar as relações gênero/sexo, nos faz pensar na pluralidade de identidades e culturas que se apresentam no contexto da escola, e que não podem ser ignorados. Não existem modelos universais de homens ou mulheres, e nem tipos corretos de ser masculino e feminino; e este é um bom motivo para se incluir o debate sobre gênero no ambiente escolar.

Candau (2011) sinaliza que a cultura escolar dominante em nossas instituições educativas prioriza o comum, o uniforme, o homogêneo, considerados como constitutivos do universal. As diferenças são ignoradas ou consideradas um problema a resolver. Dessa forma, a escola acaba por 
classificar e punir diferentes tipos de comportamentos de acordo com o padrão étnico-cultural dominante, excluindo os demais, construindo identidades subordinadas e/ou perpetuando estereótipos e preconceitos nas relações escolares e sociais. Como apontam Moreira e Candau (2003), esta discriminação pode ter caráter étnico, social, de gênero, orientação sexual, geracional, relacionado a regiões geográficas de origem, características físicas e outras.

Um elemento fundamental nesse debate é a relação entre igualdade e diferença. As noções de que as identidades discentes são construídas social e culturalmente e que estes processos são permeados pelo poder dão sustentação para a importância do papel político da educação na transformação identitária. Silva (2014) assinala que a identidade e a diferença são interdependentes e resultam de atos de criação linguística, logo, caracterizam-se pela instabilidade e pela possibilidade de novas significações, pois têm que ser ativamente produzidas. Não há como falar do ser sem relacioná-lo ao não ser. Desta maneira, a identidade sempre dependerá de outra identidade para sua concretização, pois ela é vista da perspectiva do/a outro/a. A diferenciação é o processo central pelo qual a identidade e a diferença são produzidas.

Constroem-se assim as oposições binárias (homem/mulher, heterossexual/homossexual, branco/negro, erudito/popular e outras), nas quais um termo recebe valor positivo e o outro negativo. O positivo corresponde ao que é natural e desejável socialmente - a norma, a identidade hegemônica-enquanto o negativo se refere ao que deve ser evitado, no caso a identidade hierarquicamente inferior. Estas definições envolvem disputas entre grupos sociais distintos pelo poder de definir os rumos dos recursos materiais e simbólicos da sociedade.

É importante salientar que a produção da identidade se faz a partir de um movimento que busca fixá-la e estabilizá-la e, ao mesmo tempo, de um outro movimento, que tende a subvertê-la, desestabilizá-la. Assim, as identidades, na perspectiva dos Estudos Culturais, são compreendidas como móveis, instáveis, e os contatos com a diferença acabam constituindo novas 
combinações identitárias. Seriam assim passivveis de empoderamento, o/a "diferente" poderia ganhar voz, assumir sua identidade e encaminhar suas reivindicações, passando assim para a condição da igualdade na diferença. É assim necessária a promoção de práticas que permitam às pessoas e aos diferentes grupos sociais o conhecimento e o acesso aos seus direitos, à consolidação de uma cultura democrática e ao fortalecimento do Estado de direito.

Candau evidencia a escalada, a partir da segunda metade dos anos 1970, dos direitos à diferença, "de sermos pessoal e coletivamente diferentes uns dos outros" (PIERUCCl, 1999 apud CANDAU, 2012, p.47), e é nesse contexto que caracteriza a sua perspectiva sobre direitos humanos, educação e interculturalidade. Candau (2012) cita ainda Boaventura dos Santos para defender que, em uma matriz hegemônica que não é mais da perspectiva moderna do "globalismo localizado", mas do cosmopolitanismo insurgente e subalterno, os direitos humanos devem ser reconceitualizados como interculturais. (SANTOS, 2006, p. 441-442). Nesse sentido, indica que para o sociólogo os direitos humanos não devem ser concebidos de forma abstrata, na matriz hegemônica própria da modernidade, mas na segunda perspectiva, que se refere a um dos processos que caracterizam a globalização que surge dos grupos locais, das organizações da sociedade civil, enfim, de baixo para cima, o que pressupõe a ressignificação dos direitos humanos. Para tanto, haveria que ter a superação do debate entre universalismo e relativismo cultural, o pressuposto que todas as culturas possuem concepções da dignidade humana e que nenhuma cultura é completa, nenhuma delas dá conta de toda a riqueza do humano.

A partir dessas considerações, a autora aponta para o caráter polissêmico da palavra "multiculturalismo" (CANDAU,2008), o que pode ser percebido pela constante necessidade de adjetivá-la (multiculturalismo conservador, liberal, celebratório, crítico, emancipador, revolucionário entre outros). No entanto, é possível reduzir a diversidade de sentidos atribuídos ao termo a três fundamentais: (i) multiculturalismo assimilacionista: favorece que todos se integrem na sociedade e sejam incorporados à cultura 
hegemônica, mas não se mexe na matriz da sociedade, invisibilizando suas referências identitárias de origem. No caso da educação, promove-se uma política de universalização da escolarização, todos são chamados a participar do sistema escolar, mas sem que se coloque em questão o caráter monocultural presente na sua dinâmica; (ii), multiculturalismo diferencialista reconhece os diferentes grupos culturais, promove um tratamento não discriminatório em matéria de direitos civis, políticos e sociais, mas mantém os grupos isolados e separados, terminando por favorecer a criação de verdadeiros apartheids socioculturais; e (iii) multiculturalismo interativo, que Candau também denomina interculturalidade, perspectiva à qual se alinha, que parte do princípio de que a cultura não pode ser vista como espaço sem conflitos, e de seu comprometimento com a busca pela justiça social, entendendo as representações de raça, gênero e classe como produtos de lutas sociais e relações de poder. É nesse sentido que esta abordagem propõe a inter-relação entre diferentes sujeitos e grupos socioculturais presentes em uma determinada sociedade.

Catherine Walsh (2009a) ajuda a refletir sobre a possibilidade de desconstrução de visões dicotômicas e binárias a partir do que denomina "educação intercultural", distinguindo três concepções principais desta no continente latino-americano. Nesse empreendimento, evidencia as limitações de noções como a "relacional" que meramente advogam o contato entre culturas e sujeitos, ou a "funcional", assumida como discurso oficial em um enfoque que não questiona o modelo sociopolítico vigente na maior parte dos países, marcado pela lógica neoliberal excludente e concentradora de bens e poder, minimizando os conflitos e a assimetria do poder. É em uma perspectiva decolonial, a qual fornece elementos para reflexão sobre possíveis limites das formas como o multiculturalismo vem sendo frequentemente abordado, que Walsh questiona as diferenças e desigualdades construídas ao longo da História entre diferentes grupos socioculturais, étnico-raciais, de gênero, orientação sexual, entre outros. A partir da perspectiva de "colonialidade", dialogando com Paulo Freire e Franz Fanon, a estudiosa aponta para a relevância de uma perspectiva 
intercultural assumida de forma crítica, como ação, projeto e processo que procura intervir na refundação das estruturas e ordenamentos de uma sociedade em que ainda prevalece uma matriz da colonialidade do poder (Walsh, 2009a, 2009b). Trata-se, assim, da construção de "novas" sociedades que assumam as diferenças como constitutivas da democracia e sejam capazes de construir relações novas, o que supõe empoderar aqueles/as que foram historicamente oprimidos.

Esses processos de opressão e desigualdades a que se refere Walsh suscitam uma reflexão sobre a questão dos direitos humanos e a crescente importância da educação para a construção de uma sociedade plural e inclusiva. Recentemente, as violações aos direitos humanos multiplicam-se, podendo ser identificados retrocessos e apoio de setores da sociedade a estas violações. Os direitos humanos possuem íntima relação com as sociedades democráticas. "A formação para o exercício de uma cidadania ativa e a participação nos esforços pela democratização da nossa sociedade, nas suas diferentes dimensões, inclui necessariamente trabalhar a problemática dos direitos humanos" (CANDAU, 2013, p. 311). Não basta criar apenas leis. Se elas não forem internalizados no imaginário social, não se construirá uma cultura dos direitos humanos e é neste aspecto que a educação formal é de suma importância.

É importante ter presente que os direitos humanos são historicamente construídos e não brotam espontaneamente da dinâmica social. São conquistas históricas e frutos de muitas lutas. Trata-se de educar para mudar o status quo, para questionar as desigualdades sociais, para ocupar seu lugar no mundo e reivindicar. Para que isto aconteça seria essencial oferecer à criança e ao/à jovem a oportunidade de viver com outras crenças e valores, para além daquelas da família, de serem expostos/a às contradições, de verem acolhidas e discutidas suas experiências de vida, as situações com as quais se defronta no cotidiano.

Trata-se, em outras palavras, de formar indivíduos mais capazes de lidar com um mundo que é complexo, que passa por inúmeras transformações de ordem tecnológica, social e cultural. Novas 
configurações familiares, preconceitos em torno do diferente (seja por questões de sexualidade e gênero, afiliação religiosa ou outro aspecto), violência doméstica, incluindo pedofilia, fazem parte do cotidiano dos/as alunos/as.

Não basta que a enunciação dos direitos seja guiada pela noção de igualdade formal, em um sentido universal, desconsiderando fatores que interferem diretamente na fruição de direitos, como por exemplo: a raça/etnia, gênero e orientação sexual. Assim, enfatizamos que a perspectiva de gênero é importante para se pensar a questão dos direitos humanos, e nesse sentido devemos lembrar a situação daqueles/as que se desviam da norma, como os homossexuais, bissexuais, travestis e transgêneros, e o quanto são alvo de discriminação em sociedades marcadas pela violência, exclusão e violação de direitos como a nossa

Na perspectiva que aqui defendemos os direitos humanos não devem ser negados com base na orientação sexual, identidade de gênero ou qualquer outra marcação de diferença. Acreditamos, ainda, que as diferenças não devem ser ignoradas e as contradições devem aparecer para formar cidadãos que se abram para o debate e para entender a complexidade das relações entre o "eu" e o/a "outro/a".

A educação, nessa perspectiva, questiona conhecimentos considerados universais e monoculturais etnocêntricos, bem como as dinâmicas habituais dos processos educativos, desvinculados dos contextos socioculturais dos sujeitos que deles participam. É um desafio para o/a docente promover processos de desconstrução e de desnaturalização de preconceitos, discriminações e hierarquizações que impregnam as relações sociais e educacionais, para favorecer processos de "empoderamento" coletivos e individuais.

É neste sentido que se deve enfatizar dinâmicas participativas, a utilização de múltiplas linguagens e estimular a construção coletiva, não se tratando de momentos pontuais, mas da capacidade de desenvolver projetos que suponham uma dinâmica sistemática de diálogo e construção conjunta entre diferentes pessoas e/ou grupos de diversas procedências 
sociais, étnicas, religiosas, culturais e outros/as, promovendo o reconhecimento do/a outro/a e enfrentando a assimetria de poder, articulando políticas de igualdade com políticas de identidade.

"Calar" o/a professor/a, fazê-lo/a ignorar tais questões, seria isto possível e desejável? Para os/as teóricos/as críticos, a pedagogia é sempre política, pois está conectada à luta pela agência; neste sentido, Giroux (2016) afirma que fazer a pedagogia mais política supõe ficar mais atento/a em relação àqueles tantos "momentos em que identidades estão sendo produzidas e grupos estão sendo construídos, ou objetos estão sendo criados" (p. 57, tradução nossa). O entendimento trazido pelos Estudos Culturais de que as identidades estão em estado de continua construção e mudança remete ao papel crucial do/a professor/a, para detectar estes momentos e neles interferir, através de esclarecimentos, reflexões, debates.

Para a implementação da educação em direitos humanos, é necessário "desnaturalizar" a posição que supõe que basta a transmissão de conhecimentos sobre Direitos Humanos que necessariamente a educação em Direitos Humanos estará presente. Esta educação não é apenas o desenvolvimento de uma série de atividades esporádicas sobre temas relacionados com os direitos humanos, sem articulação entre elas ou um conteúdo presente em apenas uma disciplina. Além disso, deve ser dada valoração especial aos relatos de histórias de vida relacionadas às violações ou à defesa dos direitos humanos, apresentadas pelos próprios participantes, por meio de entrevistas, matérias de jornais ou informes de outros meios de comunicação. (CANDAU, 2013; CANDAU; SACAVINO, 2013).

O papel político da pedagogia é importante e se contrapõe a investidas como as aqui verificadas que atribuem ao/à docente, ações como "tentar impingir suas próprias ideias", "cooptação político ideológica", e os/as qualifica como "abusadores de crianças e adolescentes".

\section{CONSIDERAÇÕES FINAIS}

A problemática aqui tratada integra a gama de inúmeros problemas e desafios constitutivos dos encaminhamentos políticos e culturais excludentes 
que marcam o cenário brasileiro atual e guardam desdobramentos importantes nos campos do currículo e do ensino. Os avanços obtidos no cerceamento da liberdade docente, através de ataques à chamada "ideologia de gênero" que evidenciamos pela compilação de leis citadas e comentadas, assim como a demonstração de força pelas correntes conservadoras da sociedade, com reações ainda frágeis das forças progressistas, tornam claro o caminho perigoso através do qual os destinos da educação vêm sendo traçados. Fica cristalina a ameaça de censura aos/às docentes de todo o país, por um grupo que considera que o exercício da atividade docente é incompatível com a liberdade de expressão.

A disputa por diferentes narrativas, com a questão semântica ocupando lugar central, ficou evidenciada no embate de forças de poder discutido, no qual a direita em grande medida controla o discurso social. 0 campo dos Estudos Culturais e particularmente uma visão de multiculturalismo crítico, ligada à questão dos direitos humanos, conforme aqui problematizados, nos parecem oferecer referencial teórico/prático de grande valia no contexto discutido.

Verificamos ameaças a avanços obtidas a partir de 1980, quando os nossos currículos, a partir de uma teorização crítica e mais tarde com respaldo nos Estudos Culturais, passaram a incorporar temáticas relacionadas a questões de classe social, de desigualdade, das identidades e diferenças, questões de raça e gênero. Frente a tais ameaças, as novas dinâmicas sociais, não só de gênero, mas também de raça, geração e etnia requerem abordagem corajosa. No cenário complexo em que se dá a educação escolar hoje, marcada por retrocessos de várias ordens, ressaltamos o papel essencial de professores/as bem preparados, que consigam dar visibilidade às diferenças, que lancem mão de um conjunto de práticas e metodologias para fortalecer as insurgências e as resistências. Como enfatizado por Michael Apple, em entrevista dada a docentes universitários brasileiros, o ensino deve se conectar com a vida de todas as crianças que estão na escola e com as lutas dos movimentos sociais para 
transformar as vidas dos pais e alunos (filhos). (SILVA; MARQUE; GANDIN, 2012). Esses avanços estão sendo ameaçados, como vimos aqui.

Finalizamos salientando a relevância da liberdade de expressão de gênero, entendida como direito no contexto atual de retrocessos que vivemos não apenas no Brasil, mas em um âmbito internacional. Nesse contexto, enfatizamos a importância de a sociedade civil em geral, suas associações acadêmicas e movimentos sociais ativamente se posicionarem e reagirem às afrontas sociais e à democracia. E por fim, não menos importante, enfatizamos o papel político do/a docente, central na implementação de uma pedagogia que, na mencionada perspectiva da interculturalidade crítica, potencialize a consolidação de identidades, individuais e coletivas, oferecendo a oportunidade de a criança viver com diferentes crenças e valores e de se empoderar na busca de seus direitos. Visto que os textos aprovados continuam a fazer menção à "erradicação da discriminação", esta pode ser a porta de entrada e justificativa para a permanência destas discussões na escola.

\section{REFERÊNCIAS}

ALAGOAS. Lei 7800 de 5 de maio de 2016, Institui, no âmbito do sistema estadual de ensino, o programa "escola livre", Diário Oficial Estado de Alagoas, Maceió, 9 de maio de 2016, p. 137, 2016.

ALGEBAILE, E. Escola sem Partido: o que é, como age, para que serve. In: FRIGOTTO, G. (org.) Escola "sem" Partido - Esfinge que ameaça a educação e a sociedade brasileira. 1ed. Rio de Janeiro: UERJ, 2017.

BÁRBARA, I. S. M. S.; CUNHA, F. L.; BICALHO, P. P. G. Escola sem Partido: visibilizando racionalidades, analisando governamentalidades. In: FRIGOTTO, G. (org.) Escola "sem" Partido - Esfinge que ameaça a educação e a sociedade brasileira. led. Rio de Janeiro: UERJ, 2017.

\section{BARROSO, R. Arguição de descumprimento de preceito fundamental 461}

Paraná. Disponível em:

http://stf.jus.br/portal/processo/verProcessoAndamento.asp? numero $=461$ \& cl asse $=$ ADPF\&origem $=A P \&$ recurso=0\&tipo Julgamento $=M$ Acesso em 5 de out. 2017, 2017a.

BARROSO, R. Medida cautelar na ação direta de inconstitucionalidade 5.537 alagoas. Disponível em: http://s.conjur.com.br/dl/liminar-suspende-leialagoas-criou.pdf Acesso em 5 de out. 2017, 2017b. 
BEAUVOIR, S. O Segundo Sexo. Rio de Janeiro, Nova Fronteira, 1980.

BENTO XVI. Discurso à Cúria Romana por Ocasião dos votos de Feliz Natal. Cidade do Vaticano, 22 dez. 2008.

BENTO XVI. Discurso à Cúria Romana na Apresentação de Votos Natalícios. Cidade do Vaticano, 21 dez. 2012.

BRASIL. PROCURADORIA FEDERAL DOS DIREITOS DO CIDADÃO (PFDC). Nota técnica 01/2016 PFDC, Brasília, 21 de jul. de 2016 a.

BRASIL. PGR questiona leis de seis municípios que proíbem material sobre ideologia de gênero em escolas, 16 de junho de 2017. Disponível em http://pfdc.pgr.mpf.mp.br/informativos/edicoes-2017/junho/pgr-questionaleis-de-seis-municipios-que-proibem-material-sobre-ideologia-de-genero-emescolas/ Acesso em 5 de out. 2017.

BRASIL. MINISTÉRIO DA EDUCAÇÃO (MEC). MEC justifica ação contra lei que impede opinião em Alagoas, Assessoria de Comunicação Social, 10 de maio de 2016. Disponível em http://portal.mec.gov.br/component/content/index.php? option=com_conte nt\&view=article\&id=3611 1:mec-justifica-acao-contra-lei-que-impede-opiniaoem-alagoas \& catid=222\&ltemid=86 Acesso em 26 de out. $2016.2016 \mathrm{~b}$

BRASIL. CONSELHO NACIONAL DE EDUCAÇÃO (CNE). Nota pública às Assembleias Legislativas, à Câmara Legislativa do Distrital Federal, às Câmaras de Vereadores, aos Conselhos Estaduais, Distrital e Municipais de Educação e à Sociedade Brasileira, Brasília, 1 de setembro de 2015. Disponível em http://www.spm.gov.br/noticias/conselho-nacional-deeducacao-emite-nota-sobre-ideologia-de-genero-nos-planos-deeducacao/nota_publica_sobre_ideologia_genero_01_09-1.pdf Acesso em 26 de out. 2016.

BRASIL. Lei 13.005 de 25 de junho de 2014, Aprova o Plano Nacional de Educação - PNE e dá outras providências, Diário Oficial da União, Brasília, 26 jun. 2014, seção 1 - Edição Extra, p. 1, 2014a.

BRASIL. Projeto de Lei N. 8053 de 2010 (da Câmara dos Deputados). Aprova o Plano Nacional de Educação para o decênio 2011-2020 e dá outras providências. Brasília, 2010.

BRASIL. Substitutivo do Senado ao Projeto de Lei da Câmara No. 103, de 2012 (PL No. 8053 de 2010, na Casa de origem), que "Aprova o Plano Nacional de Educação e dá outras providências". Brasília, 2013.

BRASIL. Projeto de Lei N. 7180 de 2014 (da Câmara dos Deputados). Altera o artigo $3^{\circ}$ da Lei 9394, de 20 de dezembro de 1996, que estabelece as diretrizes e bases da educação nacional. Brasília, 2014b. 
BUTLER, J. Problemas de gênero: feminismo e subversão da identidade. 8ed. Rio de Janeiro, Civilização brasileira, 2015.

CANEN, A.; XAVIER, G. P. M. Multiculturalismo, pesquisa e formação de professores: o caso das diretrizes curriculares para a formação docente,

Ensaio: Avaliação e Políticas Públicas em Educação., Rio de Janeiro, v. 13, n. 48, p. 333-344, jul./set. 2005.

CANDAU, V. M. Direitos humanos, educação e interculturalidade: as tensões entre igualdade e diferença. Revista Brasileira de Educação, v. 13, n. 37, p.45-56, jan./abr. 2008.

CANDAU, V. M. Diferenças culturais, cotidiano escolar e práticas pedagógicas. Currículo sem Fronteiras, v. 11, n. 2, p. 240-255, jul./dez. 2011.

CANDAU, V. M. Diferenças culturais, interculturalidade e educação em direitos humanos. Educação \& Sociedade, v. 33, n. 118, p. 235-250, jan./mar. 2012.

CANDAU, V. M. Professores/as: multiplicadores/as de educação em direitos humanos. Sociedade e Cultura, v. 16, n. 2, p.309-314, jul./dez. 2013.

CANDAU, V. M; SACAVINO, S. B. Educação em direitos humanos e formação de educadores. Educação, v. 36, n. 1, p. 59-66, jan./abr. 2013.

CASTRO, G. A. Escola sem Partido vai à justiça contra exigência de redação do Enem. Gazeta do Povo, Curitiba, 17 de julho de 2017. Disponível em: http://www.gazetadopovo.com.br/educacao/escola-sem-partido-vai-ajustica-contra-exigencia-de-redacao-do-enem-5oypovvpee7vlh2210iwnwijf. Acesso em 12 de out. de 2017.

CHADE, J.; TOLEDO, L. F. Relatores da ONU classificam 'Escola sem Partido' como 'censura'. O Estado de São Paulo, São Paulo, 13 de abr. de 2017. Disponível em: http://educacao.estadao.com.br/noticias/geral,relatores-daonu-denunciam-escola-sem-partido-e-classificam-projeto-decensura,70001737530. Acesso em 12 de out. de 2017.

CONFERÊNCIA NACIONAL DOS BISPOS DO BRASIL (CNBB). Nota da CNBB sobre a inclusão da ideologia de gênero nos Planos de Educação, Brasília, 18 de junho de 2015. Disponível em

http://www.cnbb.org.br/index.php?option=com_content\&view=article\&id=1 6732:cnbb-divulga-nota-sobre-a-inclusao-da-ideologia-de-genero-nosplanos-de-educacao\&catid=1 14\&ltemid=106Acesso em 26 de out. 2016.

CONSELHO NACIONAL DOS DIREITOS HUMANOS (CNDH). Resolução No.7 de 23 de agosto de 2017: Dispõe sobre posicionamento deste Conselho Nacional dos Direitos Humanos - CNDH na garantia de direitos e livre debate sobre gênero e sexualidade humana em âmbito escolar, 2017. 
ESCOLA SEM PARTIDO. Modelo de notificação extrajudicial: arma das famílias contra a doutrinação nas escolas. Disponível em <http://escolasempartido.org/artigos-top/552-modelo-de-notificacaoextrajudicial-arma-das-familias-contra-a-doutrinacao-nas-escolas $>$ Acesso em 26 de out. 2016.

ESPINOSA, B. R. S.; QUEIROZ, F. B. C. Breve análise sobre as redes do Escola sem Partido. In: FRIGOTTO, G. (org.) Escola "sem" Partido - Esfinge que ameaça a educação e a sociedade brasileira. led. Rio de Janeiro: UERJ, 2017.

FERREIRA, P.; GRANDELLE, R. Professores sob constante vigilância. O Globo, Rio de Janeiro, 1 de jun. de 2017. Disponível em:

http://oglobodigital.oglobo.globo.com/epaper/viewer.aspx? issue =e6102017 060100000051001001 \&page $=26 \&$ article $=5$ bc4dee3-90ee-4bc2-b6131026cc9d 11 le\&key=KNcUpEHtKuQDoNLnpZm+Zw==\&feed=rss\&google $=1$. Acesso em 12 de out. de 2017.

GIROUX, H. A. Atos impuros. Porto Alegre, Artmed, 2003.

GIROUX, H. A. Beyond Pedagogies of Repression. Monthly Review, vol. 67, n. 10, 2016.

JUNQUEIRA, R. D. "Ideologia de gênero": a gênese de uma categoria política reacionária - ou: a promoção dos direitos humanos se tornou uma "ameaça à família natural"?. In: RIBEIRO, P. R. C.; MAGALHÃES, J. C. Debates contemporâneos sobre educação para a sexualidade. led. Rio Grande: FURG, 2017.

MARIZ, R.; BARRETTO, E. Pais interferem em escolas que abordam questão de gênero nos livros e vetam conteúdos. O Globo, Rio de Janeiro, 29 de jul. de 2017. Disponível em: https://oglobo.globo.com/sociedade/educacao/paisinterferem-em-escolas-que-abordam-questao-de-genero-nos-livros-vetamconteudo-21644988. Acesso em 12 de out. de 2017.

MOREIRA, A. F. B.; CANDAU, V. M. Educação escolar e cultura (s): construindo caminhos. Revista Brasileira de Educação, n. 23, p. 156-168, maio/ago. 2003.

NOVA IGUAÇU. Lei 4576 de 16 de fevereiro de 2016, Veda a distribuição, exposição e divulgação de material didático contendo orientações sobre a diversidade sexual nos estabelecimentos de ensino da rede pública de Nova Iguaçu, Atos Oficiais Prefeitura da Cidade de Nova Iguaçu, Nova Iguaçu, 17 de fevereiro de 2016, p. 3, 2016

PENNA, F. O Escola Sem Partido como chave de leitura do fenômeno educacional. In: FRIGOTTO, G. (org.) Escola "sem" Partido - Esfinge que ameaça a educação e a sociedade brasileira. led. Rio de Janeiro: UERJ, 2017. 
PONTIFÍCIO Conselho para a Família. Família, matrimônio e "uniões de fato". Cidade do Vaticano, 26 jul. 2000. Disponível em:

http://www.vatican.va/roman_curia/pontifical_councils/family/documents/rc _pc_family_doc_20001109_de-facto-unions_po.html. Acesso em: 2 mar.2018.

RAMOS, M. N. Escola sem Partido: a criminalização do trabalho pedagógico. In: FRIGOTTO, G. (org.) Escola "sem" Partido - Esfinge que ameaça a educação e a sociedade brasileira. led. Rio de Janeiro: UERJ, 2017.

REVOREDO, Oscar A. La ideologia de género: sus peligros y alcances. Lima: Comisión Ad Hoc de la Mujer; Comisión Episcopal de Apostolado Laical, Conferencia Episcopal Peruana, 1998.

SANTOS, B. de S. A gramática do tempo: para uma nova cultura política. São Paulo: Cortez, 2006.

SCHOOYANS, Michel. El Evangelio frente al desorden mundial. Colonia del Valle: Diana, 2000. [orig.: Fayard, 1997].

SCOTT, J. W. Gênero: uma categoria útil de análise histórica, Educação \& Realidade, Porto Alegre, v. 20, n. 2, p. 71-99, jul/dez. 1995.

SILVA, M. V.; MARQUES, M. R.; GANDIN, L. A. Contradições e ambiguidades do currículo e das políticas educacionais contemporâneas. Entrevista com Michael Apple. Currículo sem Fronteiras v.12, n.1, pp.175-184, jan./abr. 2012.

SILVA, T. T. A produção social da identidade e da diferença. In: SILVA, T. T. (Org.). Identidade e diferença: a perspectiva dos Estudos Culturais. 14a ed. Petrópolis/RJ: Vozes, 2014.

SOUZA, R. F.; OLIVEIRA, T. F. A doxa e o logos na educação: o avanço do irracionalismo. In: FRIGOTTO, G. (org.) Escola "sem" Partido - Esfinge que ameaça a educação e a sociedade brasileira. 1ed. Rio de Janeiro: UERJ, 2017.

WALSH, C. Interculturalidad y (de)colonialidad: perspectivas críticas y políticas. In: CONGRESO DA ASSOCIATION POUR LA RECHERCHE INTERCULTURELLE, 12, 2009, Florianópolis. Anais... Florianópolis: UFSC, 2009a.

WALSH, C. Interculturalidade crítica e pedagogia decolonial: in-surgir, reexistir e re-viver. In. CANDAU, Vera Maria (Org.). Educação intercultural na América Latina: entre concepções, tensões e propostas. Rio de Janeiro: 7 Letras, $2009 \mathrm{~b}$.

Recebido em: 04 de maio de 2018. Aprovado em: 28 de novembro de 2018. 